ИЗВЕСТИЯ АКАДЕМИИ НАУК ЭСТОНСКОЯ ССР, ТОМ 31 ГЕОЛОГИЯ. 1982, № 1

\title{
ПЕРЕОТЛОЖЕННЫЕ ДОЧЕТВЕРТИЧНЫЕ МИКРОФОССИЛИИ В ЛЕДНИКОВЫХ И ВОДНОЛЕДНИКОВЫХ ОТЛОЖЕНИЯХ
}

Подавляющее большинство переотложенных пыльцы и спор в моренах и межморенных водноледниковых отложениях происходит из четвертичных межледниковых и межстадиальных отложений. Только незначительное количество (редко несколько десятков процентов) из них принадлежит к дочетвертичным формам, легко отличающимся от инситных пыльцевых зерен и спор по морфологическим признакам. Исключение составляет лишь пыльца некоторых третичных растений, которые могли распространяться и в раннечетвертичное время. Состав переотложенных дочетвертичных микрофоссилий в отложениях ледниковых эпох тесно связан с подстилающими их породами. Он изменяется по площади согласно изменениям выходов коренных пород. Такое явление используется при исследованиях для установления путей и направлений движения ледников. Е. А. Стенли (Stanley, 1966) считал переотложенные дочетвертичные пыльцу и споры ключем для определения исходного материала морских отложений. Более подробно переотложенные микрофоссилии, в том числе пыльцу и споры, в моренах изучала шведская ученая У. Миллер (Miller, 1977). По ее мнению, они существенно дополняют литологические исследования. Встречающиеся иногда в большом количестве мелкие минерогенные частицы $(0,002-0,6$ мм) обычно не исследуются литологически. Однако обнаруженные в составе этой фракции переотложенные микрофоссилии позволяют установить исходный материал морен, определить пути и направления движения ледников. Так, У. Миллер удалось таким способом различить древнебалтийскую и балтийскую морены, что невозможно сделать литологически.

Специальных исследований состава переотложенных дочетвертичных микрофоссилий в отложениях ледниковых эпох мы не проводили. Полученные данные были накоплены в ходе изучения четвертичных пыльцы и спор. Тем не менее выявляются некоторые закономерности в их распространении в отложениях. Так, в моренах и водноледниковых отложениях Северной Эстонии обнаружены в основном кембрийские, ордовикские и силурийские акритархи, а в отложениях Южной Эстонии среднедевонские споры, что связано с соответствующими выходами коренных пород (Лийвранд, 1976). Кроме них, особенно в Южной Эстонии, часто присутствуют карбоновые формы, что говорит о масштабах ледниковой эрозии. По-видимому, карбоновые отложения ранее имелись и на территории нашей республики, но были уничтожены во время оледенений. Встречаются споры и пыльца редких мезозойских растений Gleichenia, Podocarpus, Mohria. Чаще всего они обнаружены в более глубоких частях древних погребенных долин, например, в долине Абья-Треймани в разрезе Пуйэстеэ, расположенной в юго-западной части Эстонии. Так, во время накопления более древней среднеплейстоценовой морены, по-видимому, размывались и распространявщиеся тогда на территории Әстонии мезозойские отложения. 
На выходах верхнедевонских пород на территории Латвии из разреза Томены в долине р. Даугавы около Риги В. А. Перконсом были собраны образцы для палинологического анализа, выполненного нами. Красно-бурая морена, содержащая в основном верхнедевонские споры, наряду с которыми встречаются и карбоновые, и залегающая ниже сероватая морена, где кроме названных присутствуют и некоторые ордовикские и силурийские акритархи, свидетельствуют о разных путях движения ледников, отлагавших различные морены в окрестностях Томены.

Различный состав дочетвертичных форм обнаружен и в моренах разреза Мынту, расположенного на п-ове Сырве на о. Сааремаа (Лийвранд, Мартин, 1982). Верхняя серая морена содержит в основном ордовикские и силурийские акритархи и редкие девонские споры, а нижняя - только девонские споры. Эти морены, датированные по четвертичным пыльце и спорам как валдайские, принадлежат, по всей вероятности, к различным стадиям последнего оледенения. Во время накопления нижней морены на о. Сааремаа, видимо, распространялись еще девонские породы, которые почти не сохранились во время образования верхней морены.

Интересные данные получены по образцам морен Қанады (Dreimanis и др., в печати). В моренах на выходах ордовикских пород на северном побережье оз. Онтарио преобладают ордовикские акритархи балтисфяэридиумы и гониосфяэридиумы (рис. 1), которые найдены и в эстонских ледниковых отложениях и коренных ордовикских породах на о. Осмуссаар (Bockelie, Kjellström, 1979). Морены на выходах девонских пород южнее оз. Онтарио обогащены переотложенными девонскими спорами (рис. 2). На западе Қанады, в Британской Колумбии, морены подстилаются мезозойскими и третичными породами, что отражается и в составе переотложенных пыльцы и спор. Здесь обнаружено много пыльцы мезозойских и третичных хвойных, а также спор Gleichenia, Mohria и Aneimia (рис. 3).

Морены и водноледниковые отложения разрезов р. Вага, левого притока Северной Двины в Архангельской области, характеризуются совершенно иным составом дочетвертичных форм (Лийвранд, 1981). Встречаются пермские Striatopinites и Vittatina, переотложенные из подстилающих пермских пород (рис. 4). При этом состав их одинаковый как в средне-, так и в верхнеплейстоценовых отложениях. Это говорит о том, что источник переотложения в виде дочетвертичных пород оставался неизмененным длительное время. Однако это еще не обязательное доказательство одинакового направления движения средне- и позднеплейстоценовых ледников. Ввиду очень широкого распространения пермских отложений в этом районе ледники могли двигаться в различных направлениях по одновозрастным коренным породам и обогащаться переотложенными формами сходного состава.

Имеющиеся данные свидетельствуют о большой территориальной изменчивости состава дочетвертичных микрофоссилий в отложениях ледниковых эпох в зависимости от выходов коренных пород. В связи с этим они не пригодны для определения возраста и корреляции ледниковых отложений на обширных территориях. Например, состав переотложенных дочетвертичных форм в валдайских отложениях постоянно изменяется от Архангельской области до Южной Прибалтики, в то время как состав переотложенных из четвертичных отложений пыльцы и спор на этой же территории постоянный, и позволяет установить послемикулинский возраст этих отложений (Лийвранд, 1982). Пере отложенные из широко распространенных межледниковых отложений пыльцевые зерна не позволяют разделить стадиальные морены, как можно убедиться по сказанному выше, однако это возможно по дочет- 
вертичным формам, переотложенным из коренных пород. Изучение состава переотложенных дочетвертичных микрофоссилий дает дополнительные сведения о масштабах ледниковой экзарации, изменениях выходов коренных пород во времени и о направлениях движения ледников разных стадий и оледенений.

\section{Л ИТЕ РА Т У РА}

Л и й в ранд Э. Д. Переотложенные пыльца и споры в плейстоценовых отложениях и их роль в стратиграфни. - В кн.: Палинология в континентальных и морских геологических исследованиях. Рига, 1976, 166-178.

Л и й в ранд Э. Д. О возрасте и корреляции слоев разрезов Пасьва и Колешки Архангельской области по геологическим и палинологнческим данным. -В кн.: Геология плейстоцена Северо-Запада СССР. Апатиты. 1981,

Л и й в р а нд Э. Значение переотложенной пыльцы межледниковых термофильных древесных пород в стратиграфии. - Изв. АН ЭССР. Геол., 1982.

Л и й в ранд Э., М а р тин Л. Геологическая и палинологическая характеристика плейстоценовых отложений разреза Мынту на острове Сааремаа. - Изв. АН ЭССР. Геол., 1982.

Bockelie, T. G., Kjellström, G. Middie Ordovician acritarchs from the island of Odinsholm, Estonia. - Geol. Fören. in Stockholm Förhandlingar., 1979, 101, $205-216$.

Dreimanis, A., Li ivrand, E., R a ukas, A. The need and possibilities of using re-bedded pollen and spores in stratigraphy and paleogeography on the example of the European part of the Soviet Union and Canada (in press).

Mille r, U. Pleistocene deposits of the Alnarp Valley, southern Sweden. - In: Microfossils and their stratigraphical application. Lund, 1977.

$\mathrm{Stan}$ ley, E. A. The problem of reworked pollen and spores in marine sediments. Marine Geol., 1966, 4, 396-408.

Ннститут геологии

Академии наук Эстонской ССР
Поступила в редакцию 8/VII 1981

\section{Elsbet LIIVRAND}

\section{OMBERSETTINUD KVATERNAARIEELSED MIKROFOSSIILID LIUSTIKU- JA LIUSTIKUSULAMISVEE SETETES}

Jäätumisaegade setetes esinevate kvaternaarieelsete mikrofossiilide koostis on tihedas seoses aluspõhja avamusalade primaarsete mikrofossiilide koostisega, seetōttu saab esimesi kasutada mandrijää liikumissuundade kindlaksmääramisel, erinevate staadiumide setete liigestamisel ning kvaternaarieelsete setete levikupildi muutuste täpsustamisel.

Elsbet LIIVRAND

\section{RE-BEDDED PRE-QUATERNARY MICROFOSSILS IN GLACIAL AND AQUEOGLACIAL DEPOSITS}

Sediments of the glacial epochs contain re-bedded Pre-Quaternary microfossils from the underlying bedrock (Figs 1-4). These different forms can be used for adjusting the directions of the ice movements, the intensity of glacial erosion, the stratification of the glacial deposits and for palaeogeographical conclusions, for example, for the determination of changes in the distribution of bedrock outcrops. 

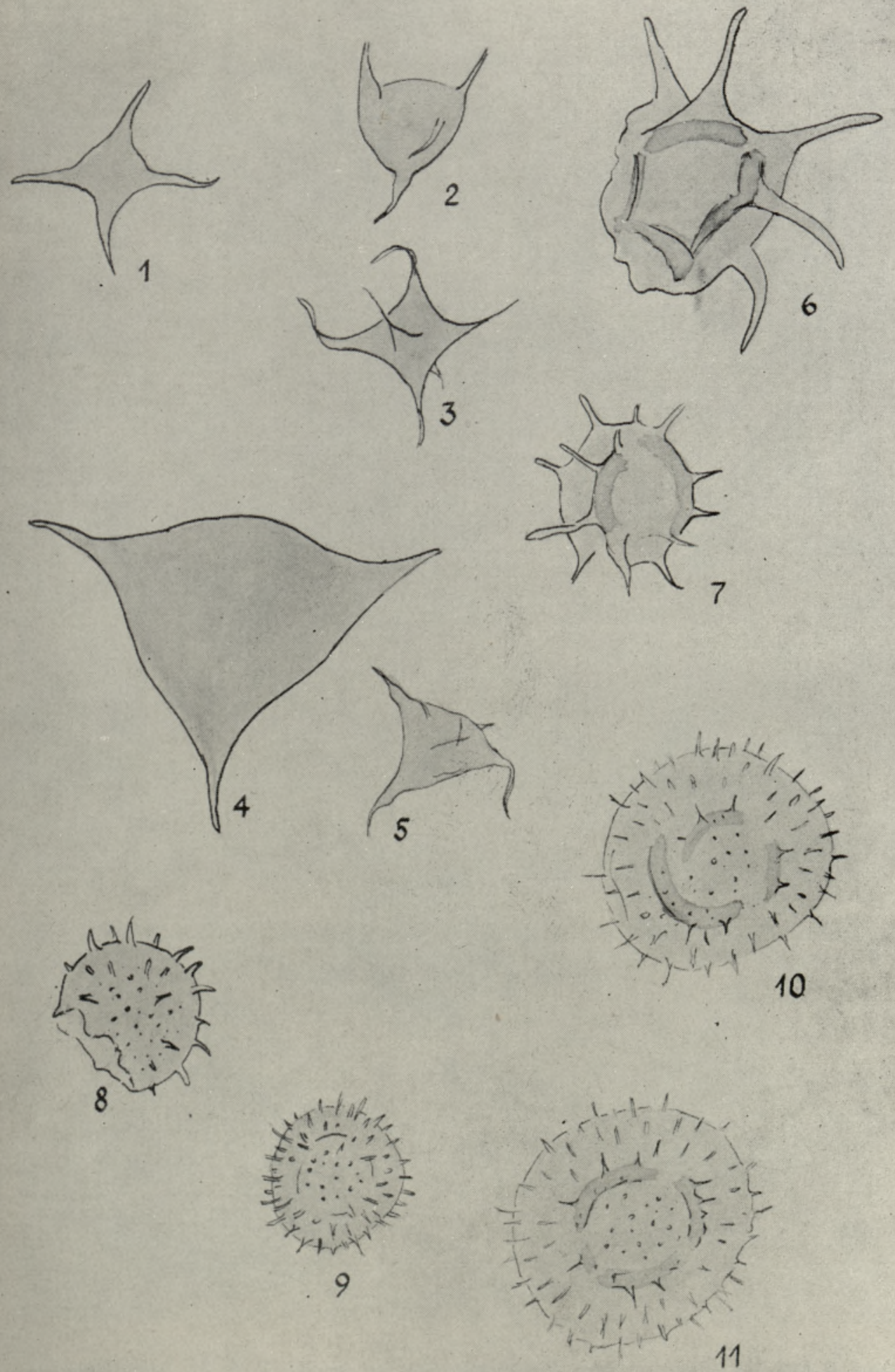

Рис. 1. Переотложенные акритархи Goniosphaeridum sp. sp. (1-7) и Baltisphaeridum sp. sp. $(8-11)$ в морене на выходах ордовикских пород севернее оз. Онтарио в Канаде. 


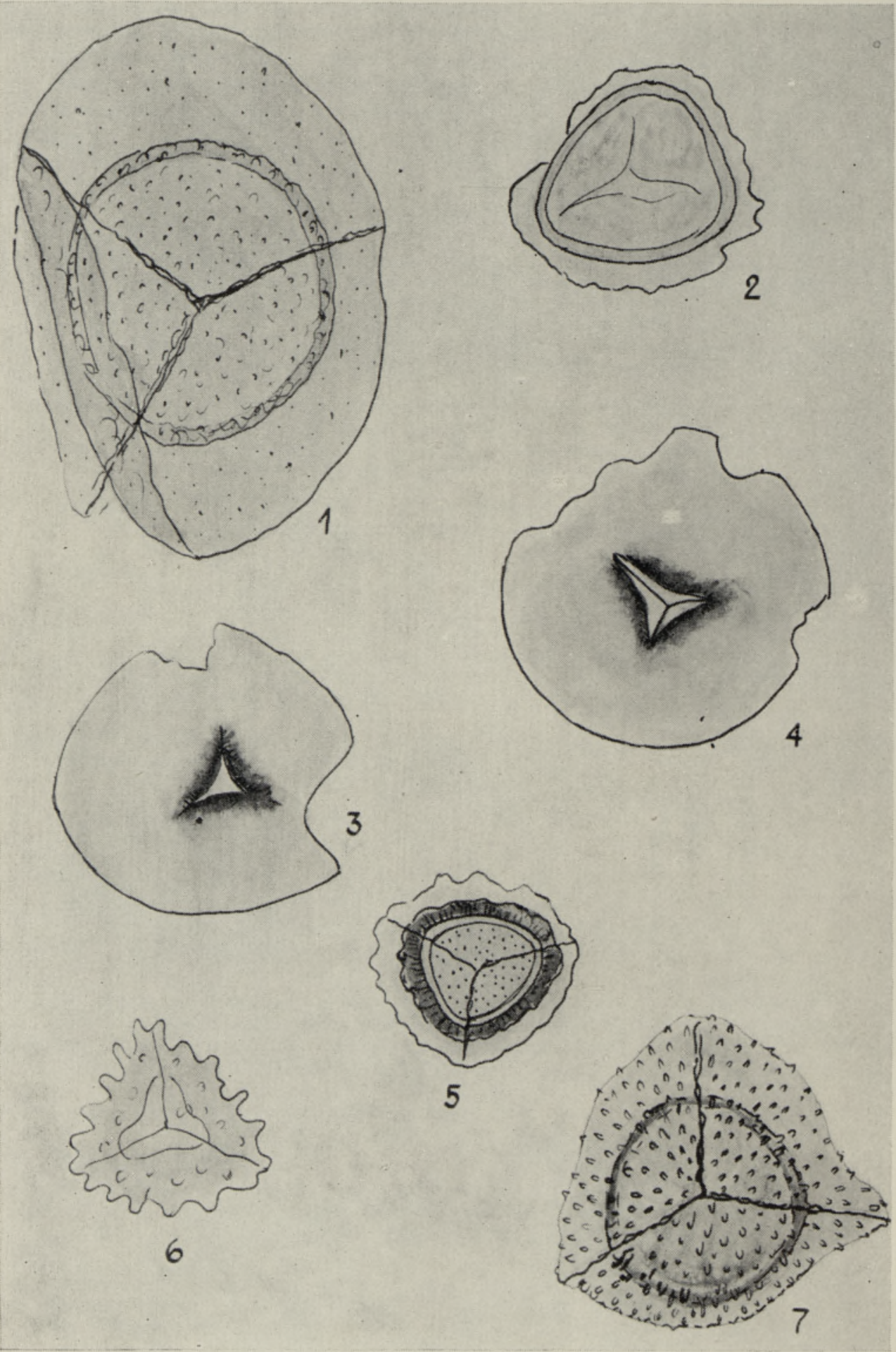

Рис. 2. Переотложенные споры Humenozotriletes sp. sp. $(1,2,5,7)$, Leiotriletes sp., $(3,4)$ и Acantotriletes sp. (6) в морене на выходах девонских пород южнее оз. Онтарно в Канаде. 

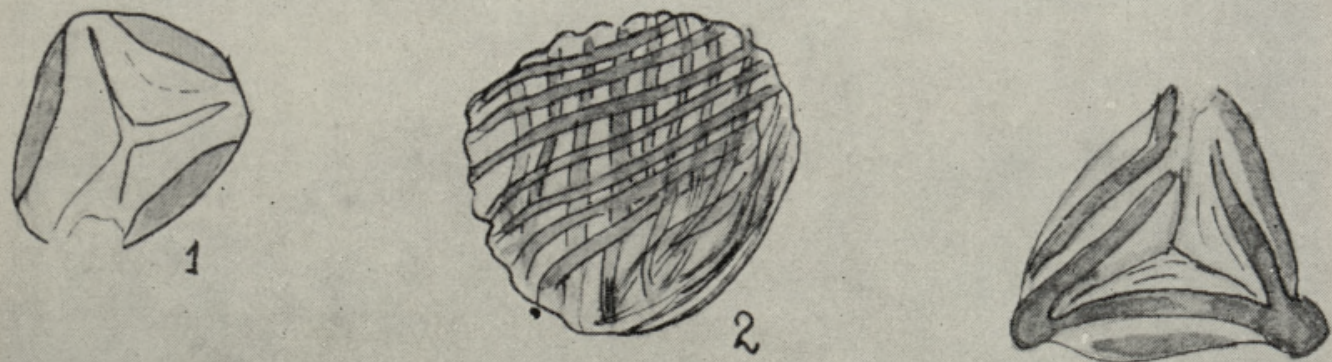

3

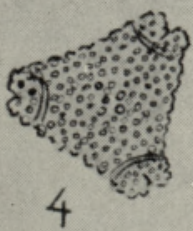

Рис. 3. Переотложенные споры и пыльца Gleichenia sp. (1), Mohria sp. (2), Aneimia sp. (3), Proteaceae sp. (4) в морене на выходах мезозойских и третичных пород в Британской Колумбии (в Канаде). 


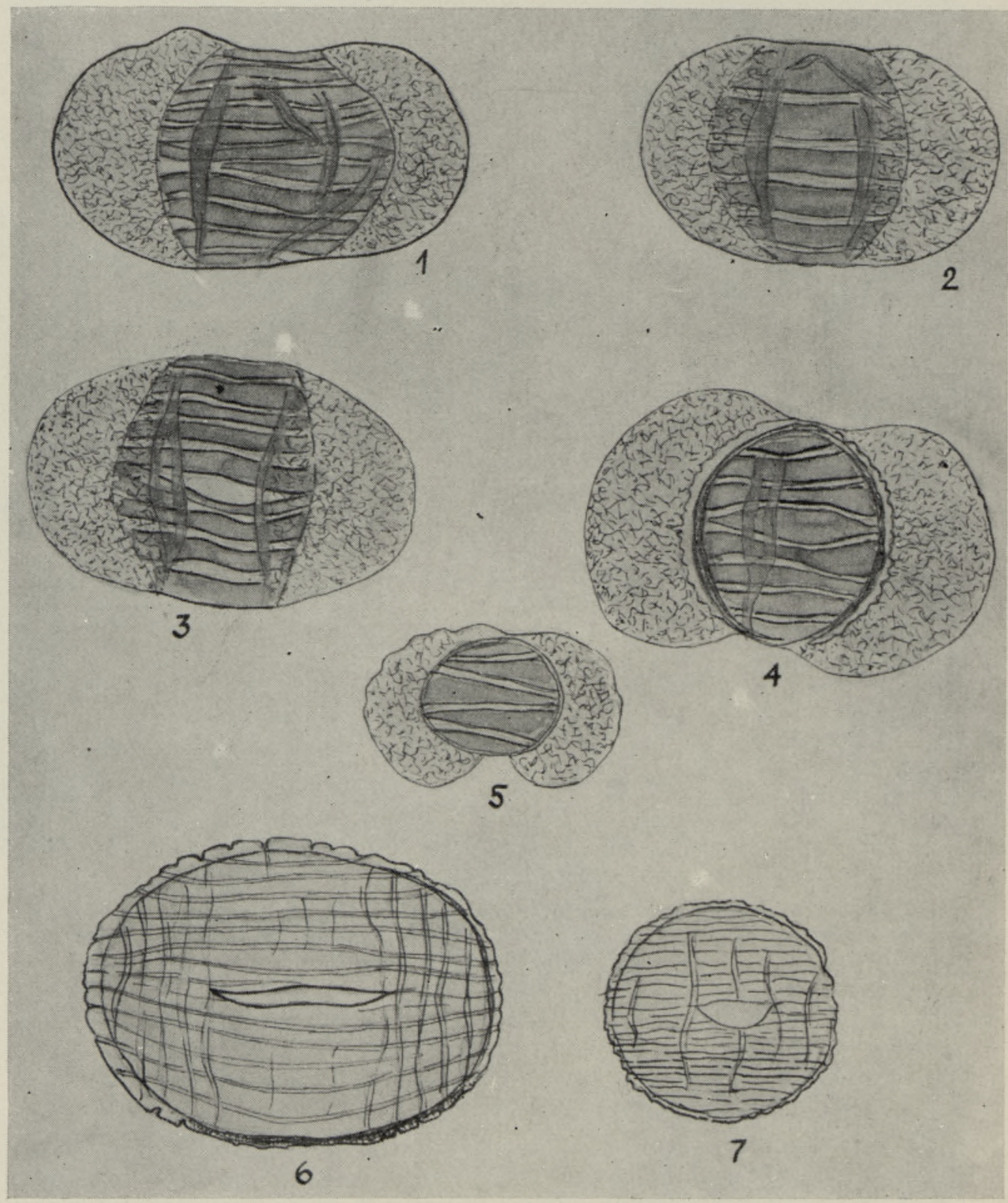

Рис. 4. Переотложенные палиноморфы Striatopinites sp. sp. $(1-5)$, Vittatina sp. sp. $(6,7)$ в отложениях средне- и позднеплейстоценовых ледниковых эпох в разрезах р. Вага Архангельской области. 